\title{
Penile injuries in children
}

\author{
Mohamed Oulad Saiad (i)
}

Cite this article as: Oulad Saiad M. Penile injuries in children. Turk J Urol 2018; 44: 351-6.

ORCID ID of the author: M.O.S. 0000-0001-6845-3936.

General Pediatric Surgery, Cadi Ayyad University, Mother and Child Unit, Mohamed VI Teaching Hospital, Marrakesh, Morocco

Submitted:

27.12.2017

Accepted:

19.02.2018

Available Online Date:

21.05.2018

Corresponding Author:

Mohamed Oulad Saiad

E-mail: mouladsaiad@gmail.com

CCopyright 2018 by Turkish Association of Urology

Available online at www.turkishjournalofurology.com

\section{ABSTRACT}

Objective: Penile injuries are not rare in children. Our aim is to establish their causes and to report our experience in the management of those accidents.

Material and methods: A retrospective study of all penile injuries presented from January 2009 to January 2017 was performed. Hemorrhage and excess of mucosa or skin remnants are the most frequent and benign injuries after circumcisions, so they were excluded from the study.

Results: Four groups were reported including the circumcision accident group, the traumatic accident group, the strangulation group and the electrocution group. The most frequent cause was circumcision accidents. We performed a penile re-implantation in one, and a glans re-implantation in another patient. Two patients underwent phalloplasty using the stumps of the remaining corpora cavernosa. We performed nine fistulae repair. Follow up showed healing without complication in the majority of the patients but recurrence of fistula was witnessed in four patients.

Conclusion: Penile injuries are frequent with a challenging management. Most of the accidents can be prevented by improving conditions of circumcision.

Keywords: Amputation; burn; circumcision; fistula; glans; penis.

\section{Introduction}

Different etiologies are involved in penile accidents that result in different types of injuries ranging from minor to serious and severe. Depending on the etiology, the severity and the consultation delay, the management can be urgent or deferred later.

Our aim is to establish the causes of penile injuries in order to prevent those accidents and to report our experience in the management of penile injuries.

\section{Material and methods}

A retrospective study was performed from January 2009 to January 2017. All patients less than 15 years old presented with penile injuries except patients with hemorrhage and penile mucosa remnants, that are the most frequent but less severe complications, of circumcisions are included in the study.

\section{Results}

Fifteen patients with different penile injuries were reported. The mean age was 5 years. Patients were divided into 4 groups depending on the etiology. The circumcision accident group (total $\mathrm{n}=11$ patients: glans amputation, $n=1$, penile amputation, $n=1$, and fistulae, $n=9$ ), the traumatic accident group (penile amputation $\mathrm{n}=1$ ), the strangulation group (total $n=2$ patients; hair tie, $n=1$, and constricting nut, $\mathrm{n}=1$ ), and the electrocution group $(n=1)$. In the traumatic accident group, a 5-year-old boy presented 4 hours after a penile amputation committed by a neighbor with a psychiatric disorder. Physical 
examination revealed that the amputation was in the base of the penis and involved the complete transection of the penis (corpus cavernosum, spongiosum and urethra) with only $1 \mathrm{~cm}$ wide skin tissue left. There were edema and signs of ischemia on the penis (Figure 1,2). After passing a Foley catheter, a macroscopic re-implantation was performed with suturing urethra and tunica albuginea. The postoperative course under intravenous antibiotics and heparin was uneventful after the regeneration of a small necrotic area of the glans (Figure 3). The catheter was removed 2 weeks later. After 3 months of

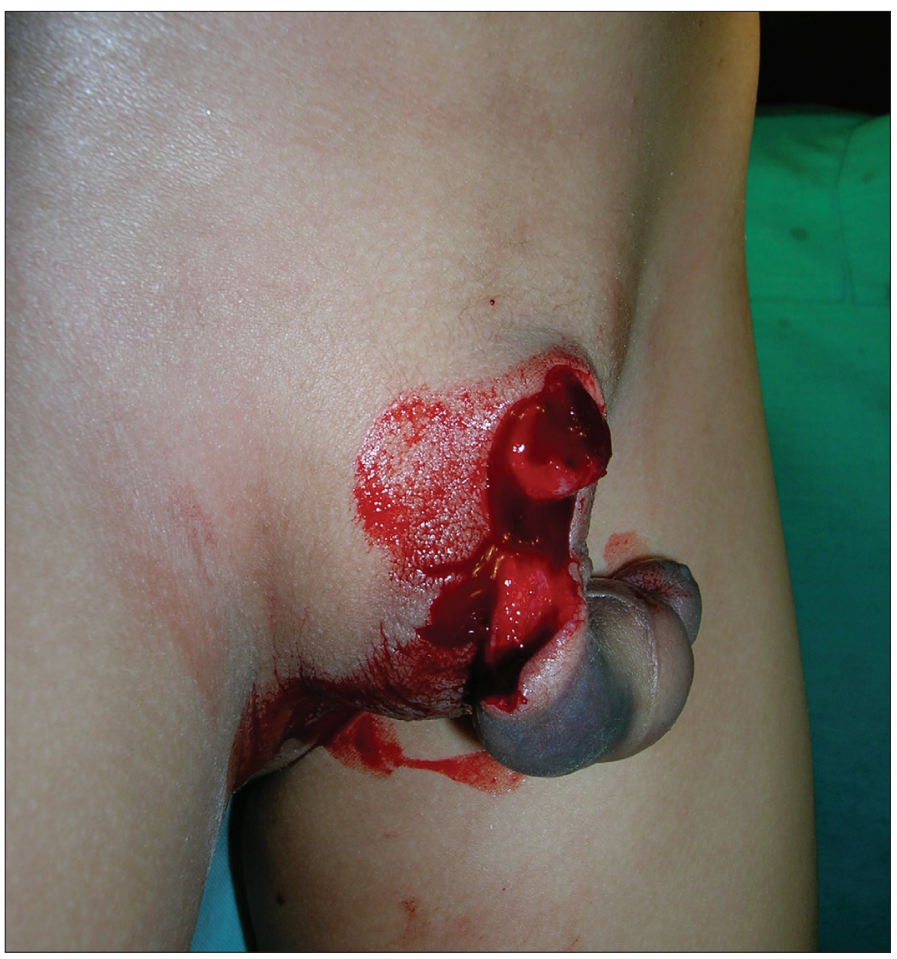

Figure 1. Lateral view of the amputated penis involving the complete transaction of the penis

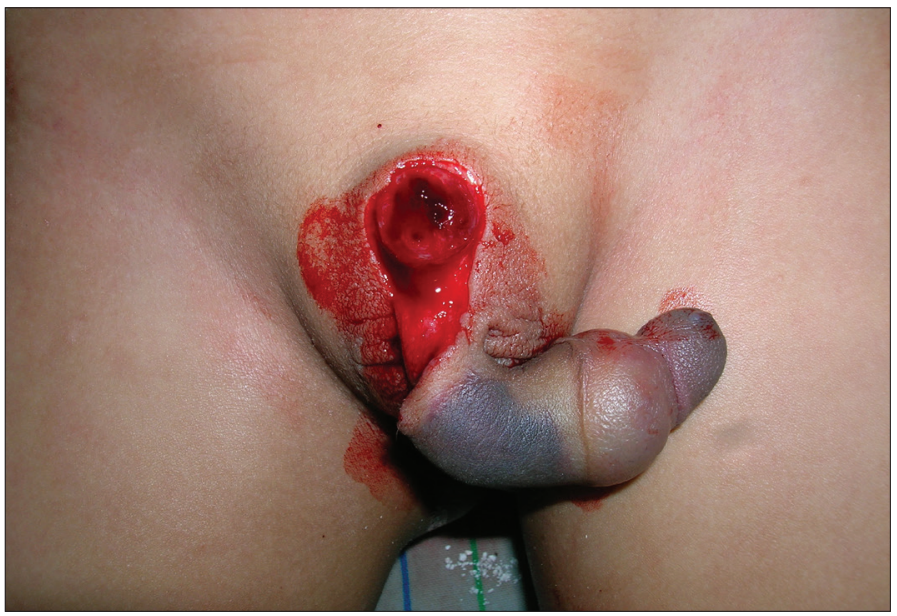

Figure 2. Frontal view of the amputed penis follow up the patient was doing well with a good urine stream at the examination (Figure 4). Because of familial problems the patient and his mother moved to another city and he was lost to further follow up. In the strangulation group, the first patient was a 6 year-old boy presented with a hair tie splitting the urethra, the patient and his mother denied the circumstances and the date of the accident. The urethra and the corpus spongiosum were completely split at the coronal area (Figure 5 ). The hair tie was removed under general anesthesia (Figure 6) and 6 months later a dissection of both ends of the urethra with anastomosis was performed. The postoperative course was uneventful; the transurethral catheter was removed on the $15^{\text {th }}$ postoperative day. After 3 years of follow-up the patient had a good urine stream (Figure 7), the glans was sensible, and morning erections were present. The second patient of this group presented with a swollen penis in a constricting nut (Figure 8). Under general anesthesia the nut was cut (Figure

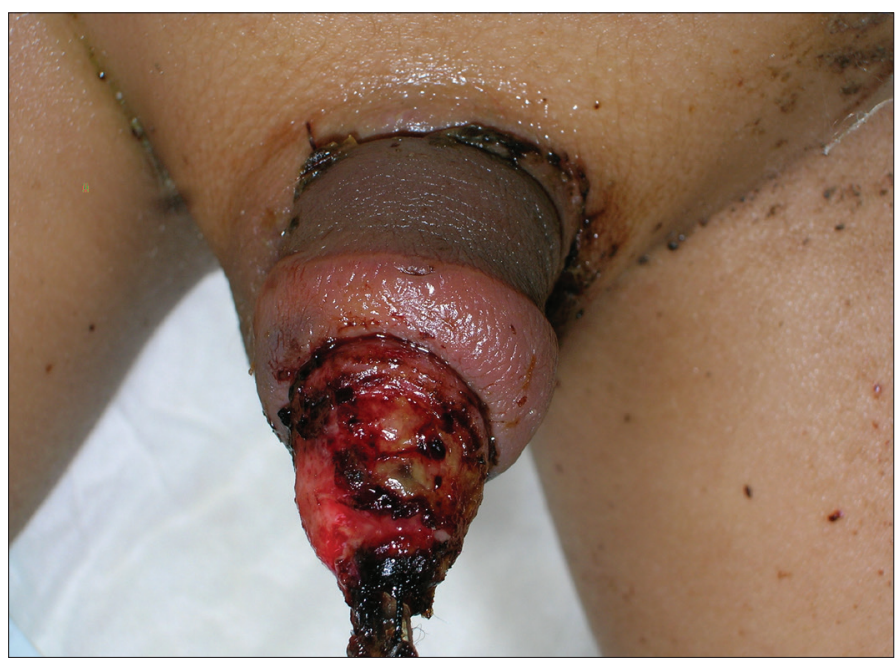

Figure 3. During the healing

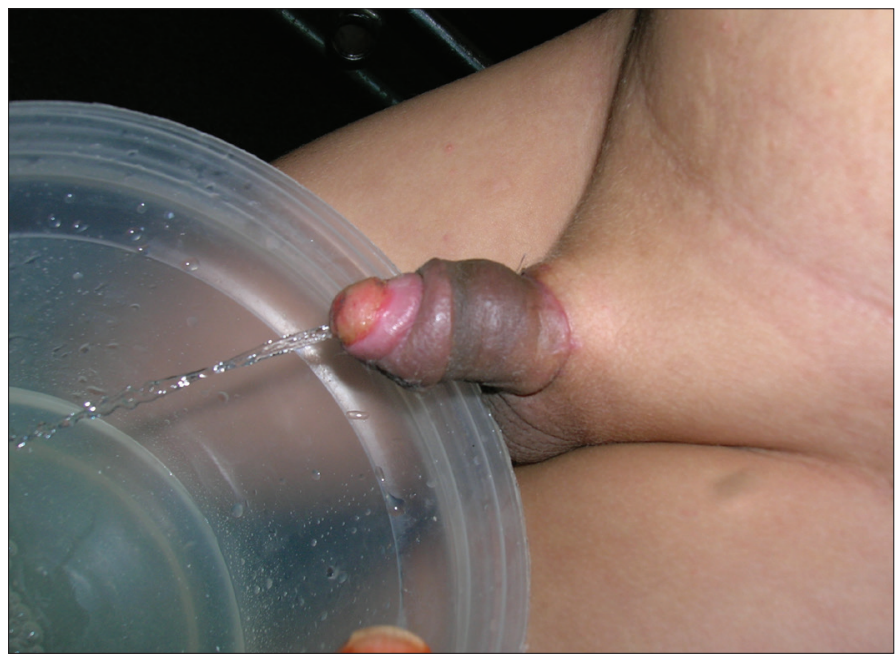

Figure 4. Good urine stream one month after reimplantation 


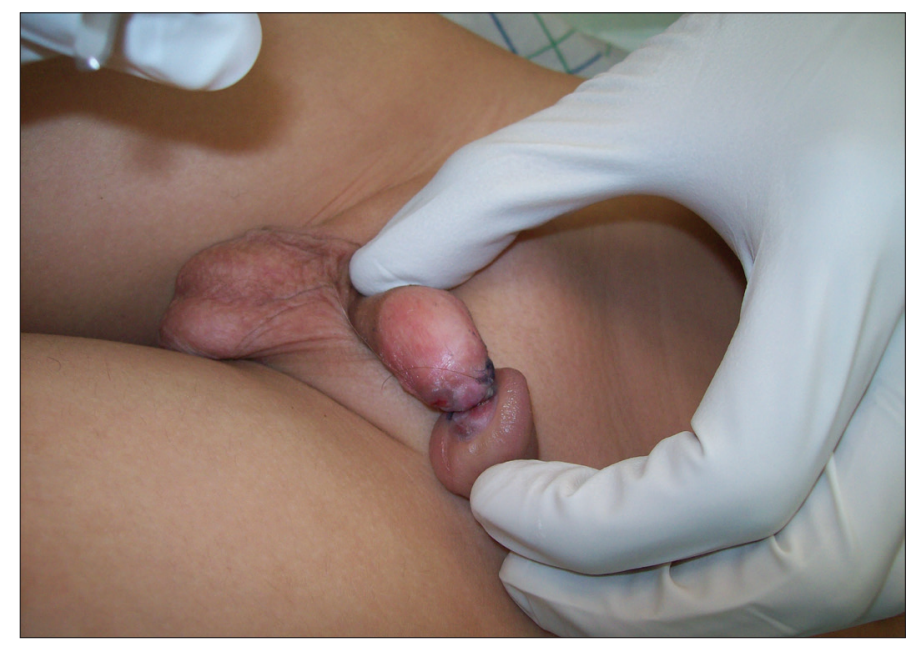

Figure 5. A hair tie splitting the urethra and spongiosum

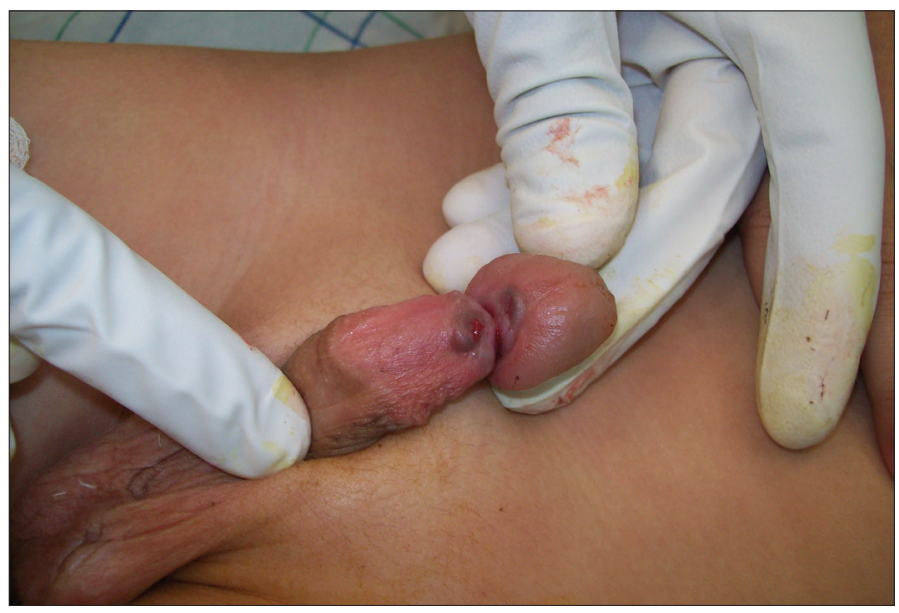

Figure 6. After removing the hair

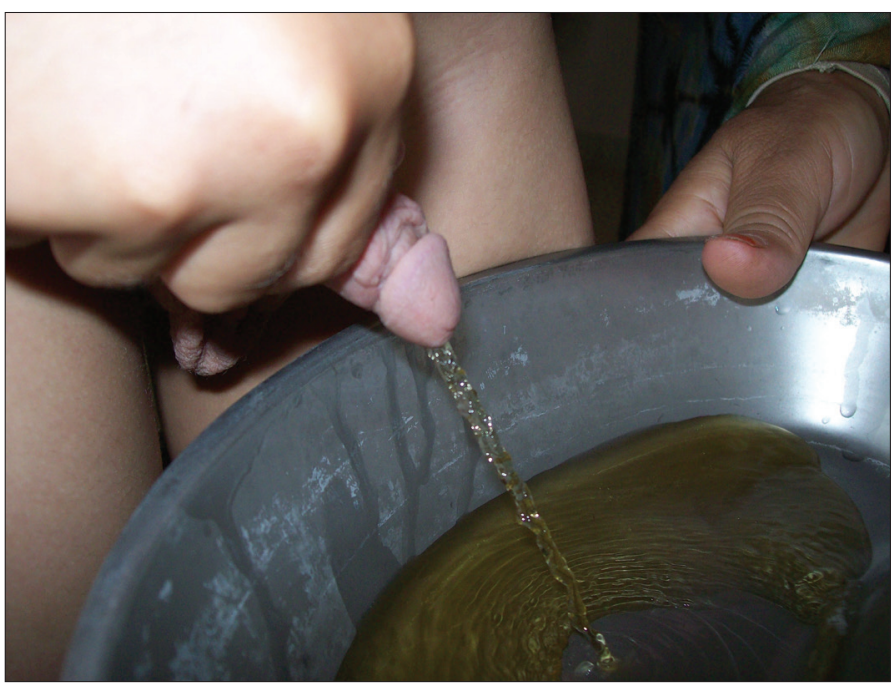

Figure 7. Good urine stream at 6 months of follow up after anastomosis
9) and five days later the edema resolved and the patient discharged. In the circumcision accident group, the patient with penile amputation presented 6 hours after the accident without the amputated penis in a tertiary center. Hemostasis was achieved and stitches between urethral mucosa and skin of the penile stump were made to prevent stenosis. The patient was referred to our center 4 months later (Figure 10). A phalloplasty was performed, the penile stump was dissected, the suspensory ligament was divided and scrotal flaps were used to cover the penis (Figure 11). The postoperative course was uneventful

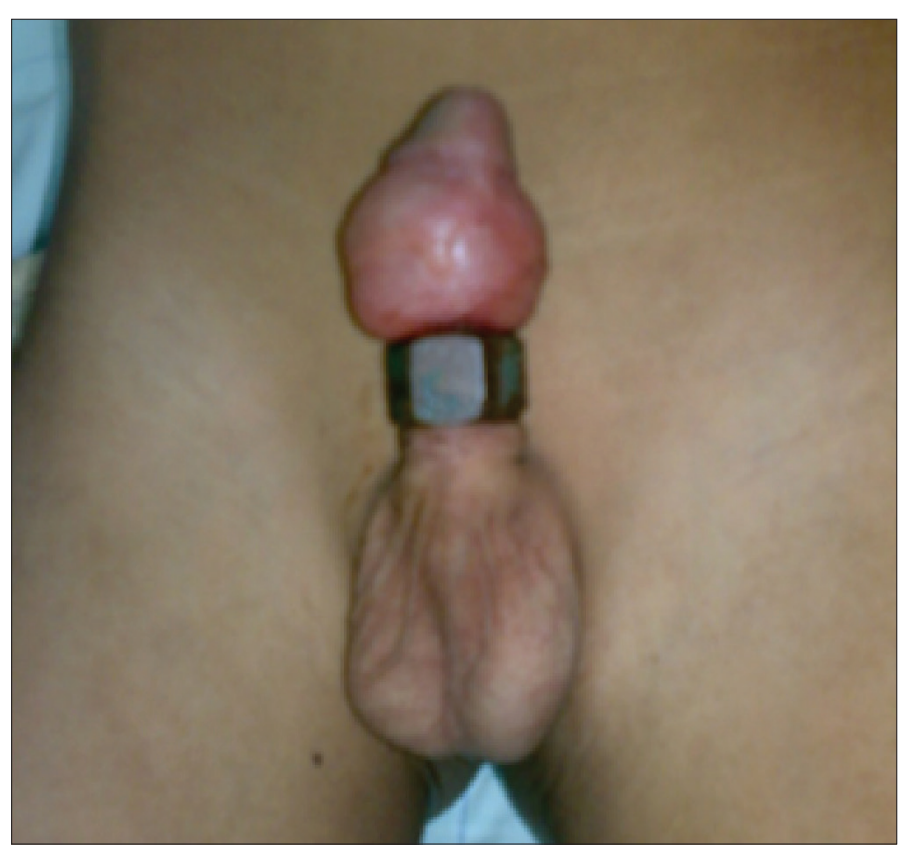

Figure 8. Constricting nut causing penile edema

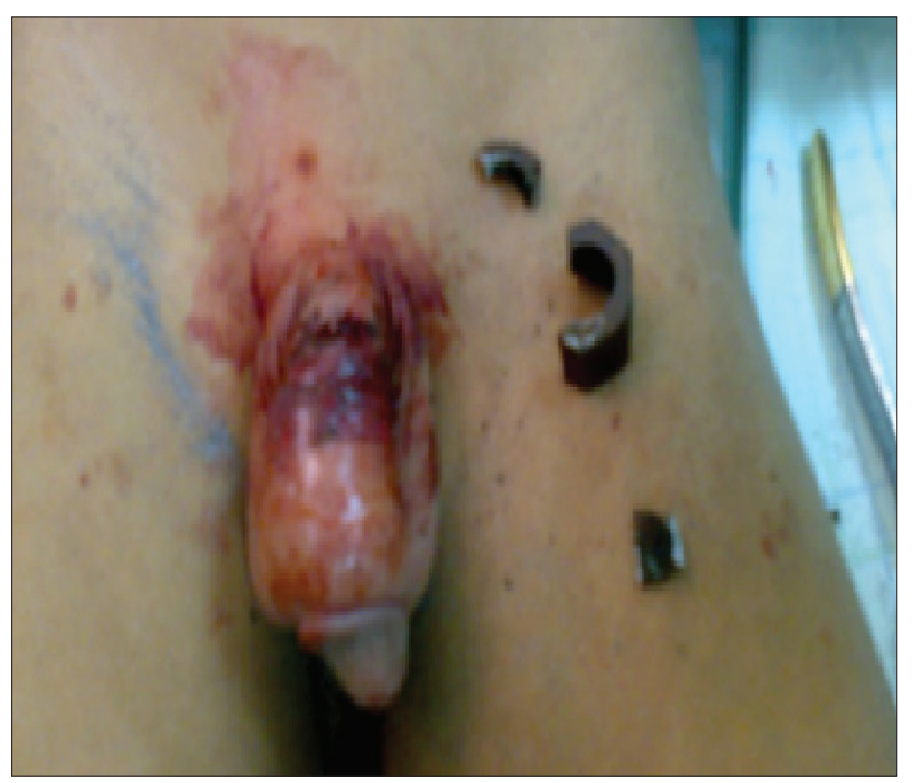

Figure 9. After cutting the nut 
with a good penile appearance. After 1 year of follow-up, the urine stream was good and the morning erections were present. The second patient with glans amputation was admitted 2 hours after the accident and a macroscopic re-implantation was performed. The postoperative course was uneventful, the stent was removed two weeks after. After 3 months of follow up the patient was doing well, with a good urine stream and morning erection was reported. Urethrocutaneous fistulae were glanular in 3, subcoronal in 5, (Figure 12) and midshaft in 1 patient. After waiting a period of 6 months after the circumcision, the bridge between the fistula and the meatus was divided, then Duplay urethroplasty and glansplasty were performed in 4 patients. A second layer was constructed by the remaining dartos in 3 , and spongioplasty in one patient. The fistulas were closed in five patients. The stent was removed on the $6^{\text {th }}$ postoperative day. During an average follow-up of 1 year, fistulas recurred in four patients. In 3 of these 4 patients fistulas were closed, and one of them underwent Duplay's procedure and glansplasty. After 6 months, Duplay urethroplasty was performed after dividing the bridge and covering the defect with a tunica vaginalis flap in three patients with a good postoperative outcome without recurrence after 1 year of follow up. The fourth patient was reoperated using a Koff's procedure but the follow-up revealed a meatal retraction with glans dehiscence.

The only patient of the electrocution group was a 13 yearold-boy referred to our center after healing of the burn with a penile necrosis 8 months after climbing a high voltage line. The clinical examination showed a depressed patient with penile loss, presence of a hypertrophic scar and the patient had a foley catheter (Figure 13, 14). A phalloplasty with dissection of the corpora cavernosa from the pubic bone was performed and the

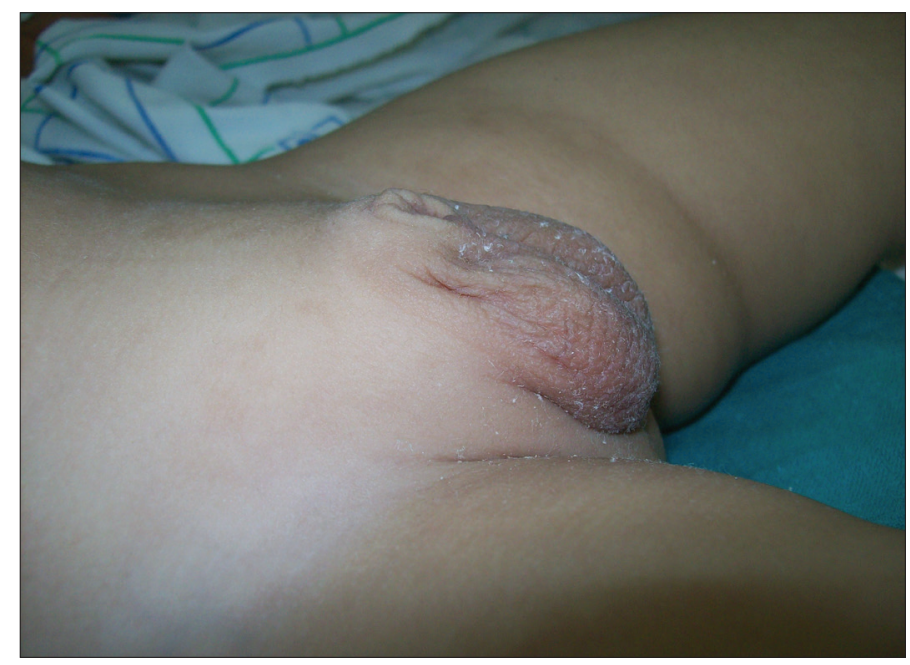

Figure 10. Penile amputation after circumcision defect was closed with scrotal flaps (Figure 15). The postoperative course was uneventful and the patient was satisfied. After one year follow-up the urine stream was good without meatal stenosis.

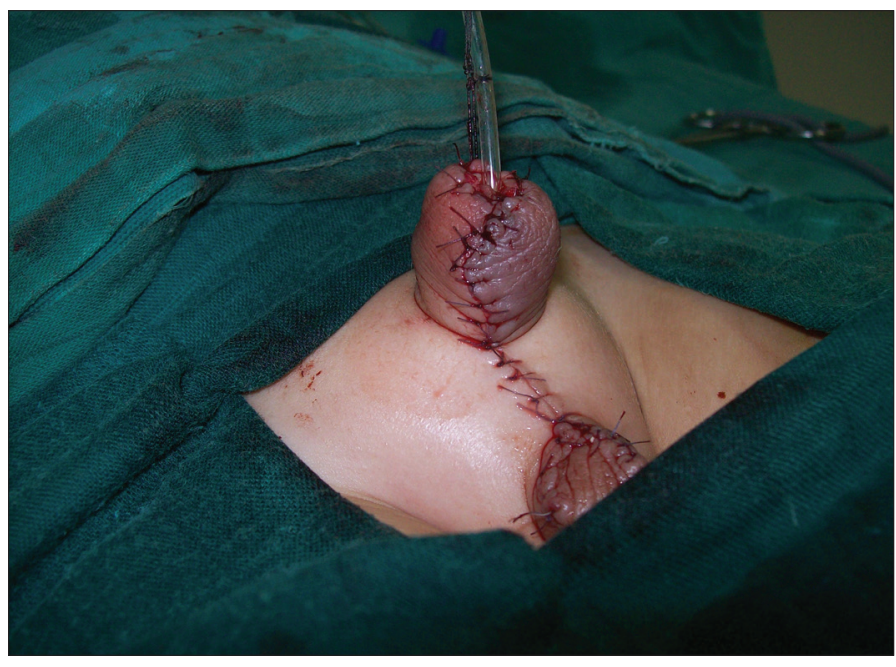

Figure 11. Phalloplasty by the dissection of the remaining corpus cavernosum and closure of the defect with scrotal flaps

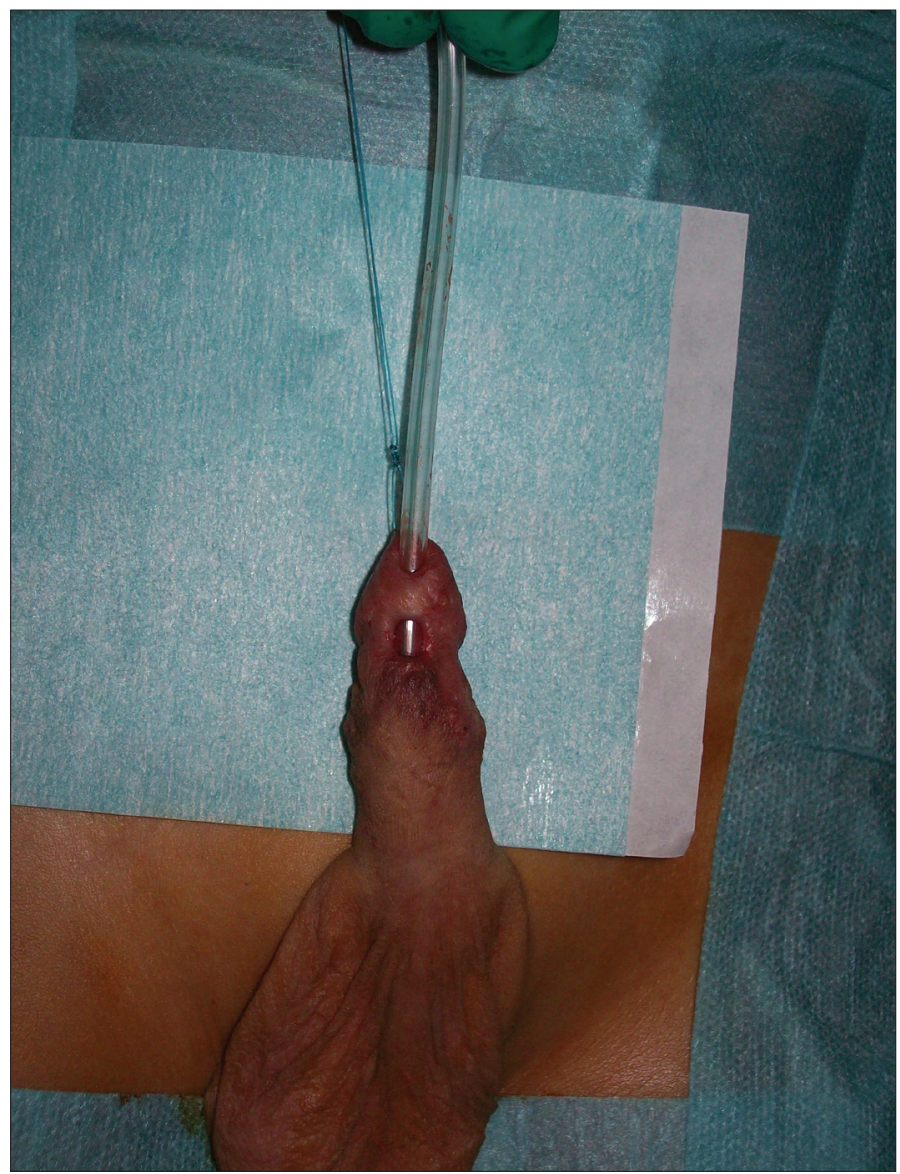

Figure 12. Glanular urethrocutaneous fistula 


\section{Discussion}

Penile injuries in children can be due to several causes: traffic accidents, iatrogenic trauma, animal bite, electrocution, zipper injuries and hair strangulation. ${ }^{[1]}$ They vary from trivial to more severe ${ }^{[2]}$ with a dreadful functional and psychosocial consequences. Patient with a penile amputation benefits from the development of microsurgery with many successful reimplantation results. ${ }^{[3]}$ Nonetheless artery, vein and nerve are difficult to identify in pediatric population. ${ }^{[4]}$ The lack of microscope, instruments and experience in microsurgery lead to macroscopic re-implantation that was first attempted in 1929. ${ }^{[5]}$ When the amputated penis is not recovered or salvaged, a phalloplasty using the cavernosum remnant after their dissection from the pubic bone ${ }^{[6]}$ and closure of the defect with scrotal

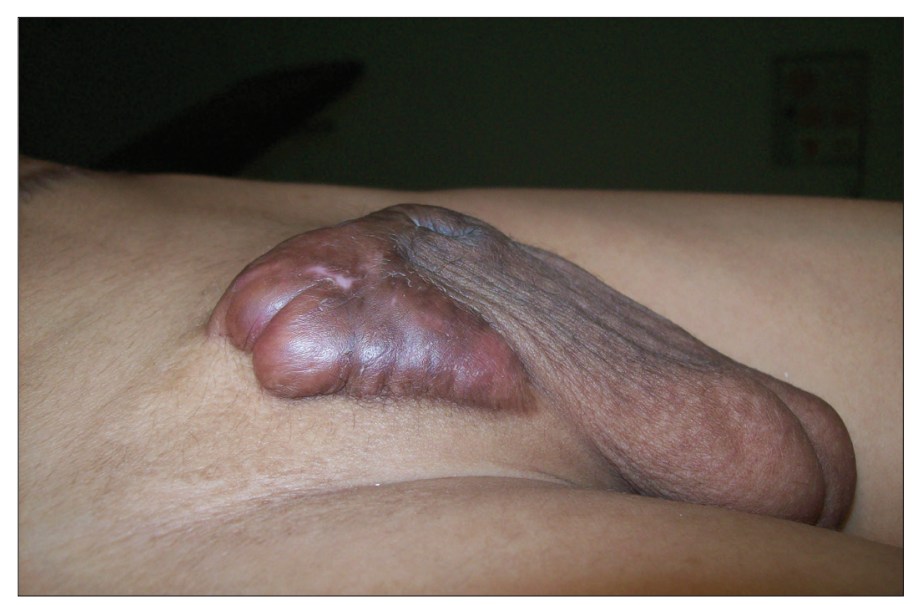

Figure 13. Lateral view of the penile necrosis after electrocution

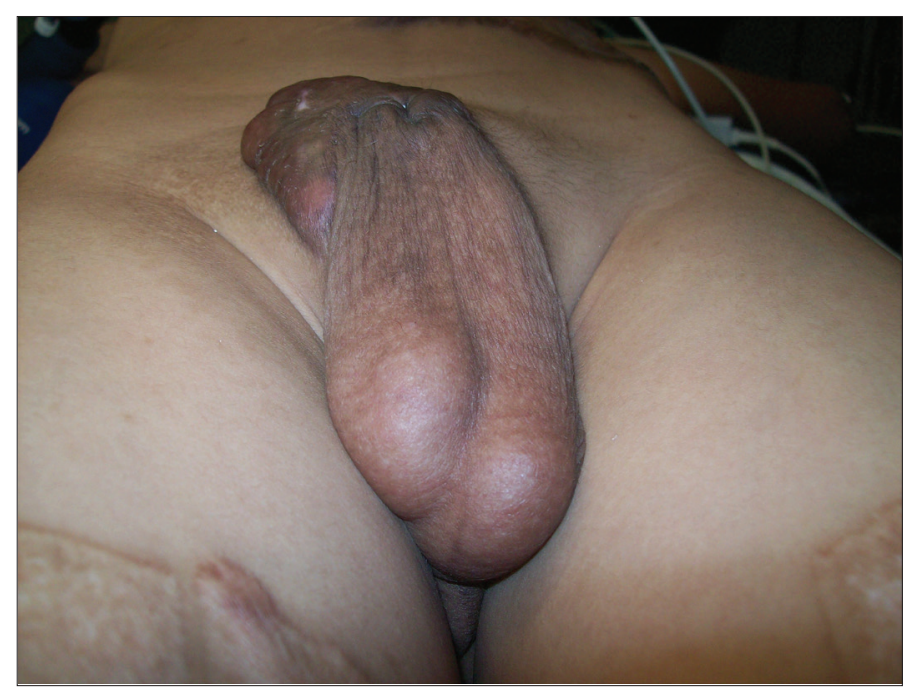

Figure 14. Frontal view of the penile necrosis after electrocution fasciomyocutaneous flaps is better than applying a thin graft. ${ }^{[6,7]}$ In the absence of the amputated penis and any residual erectile tissue, a penile transplantation has been successfully attempted in adults. ${ }^{[8]}$ Phalloplasty using different flaps is also another option when none of the above solutions could be performed. ${ }^{[8,9]}$ Because of the testosterone impact on the fetus brain and the variety of procedures, sex reassignment seems not to be a good option. The penile strangulation causes gradual swelling, ischemia and skin ulceration. In adults, it can be caused by wedding rings or rubber bands in order to improve erection. ${ }^{[10]}$ Strangulation with human hair is reported as accidental. ${ }^{[10]}$ But in our experience, we think it is deliberate in order to take revenge or with magical goals. Removal of the constricting agent at the early stage prevents complications ${ }^{[10]}$ as for the patient with nut strangulation. Urethrocutaneous fistula is not the most frequent complication of circumsion. It is reported to be due to inadvertent entrapment of excess ventral skin involving the urethra ${ }^{[10]}$ or deep sutures involving urethral wall in the frenular area. ${ }^{[11]}$ Most often, it is preferable to wait six weeks after the injury in order for the inflammation to subside before the fistula repair ${ }^{[12]}$ but sometimes a delayed fistula repair can be performed until the penile size of the child allows good tissue handling. ${ }^{[13]}$ Simple closure, Snodgrass technique, and Mathieu's perifistula based flap after separating a narrow bridge between fistula and meatus could be performed depending on the size and the location of urethrocutaneous fistula. ${ }^{[14,15]}$ In our experience, we think that urethrocutaneous fistula after circumcision might also result from excessive use of electrocautery. Because of the high risk of recurrence we think as for fistula in hypospadias surgery, we should wait a period of 6 months before the repair until the fistula mature. Penile injuries are frequent, and the management of severe accident is challenging. Nonetheless multiple procedures are available for each circumstance. Improving the conditions

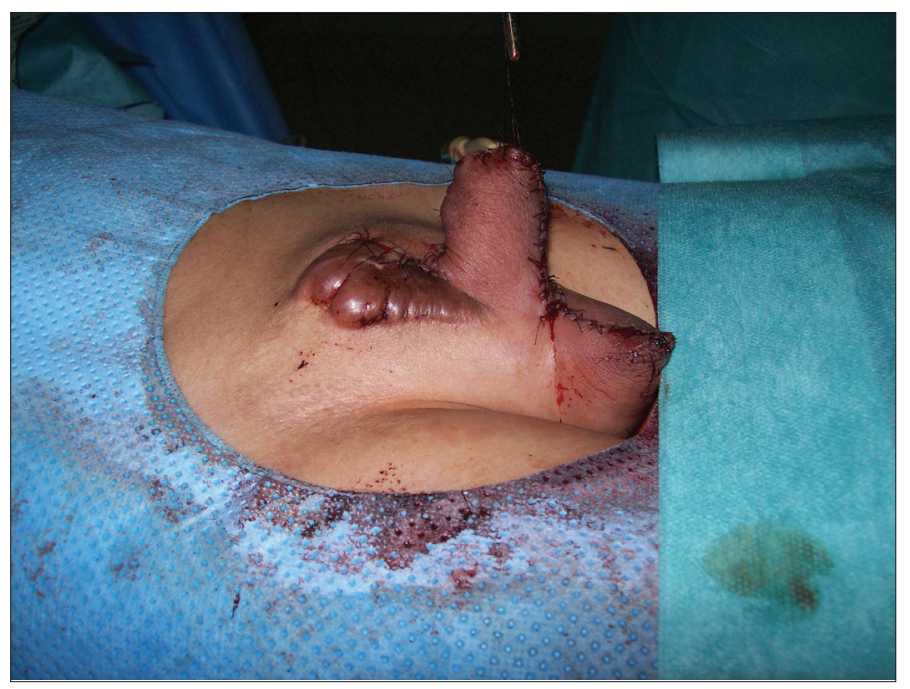

Figure 15. Phalloplasty using the remaining corpus cavernosum and closure of the defect with scrotal flaps 
of circumcision and forbidding the traditional circumcisions can prevent most of those injuries.

Ethics Committee Approval: Ethics committee approval was received for this study from the ethics committee of University Hospital Mohamed VI.

Informed Consent: Written informed consent was obtained from the parents of the patients who participated in this study.

Peer-review: Externally peer-reviewed.

Conflict of Interest: Author have no conflicts of interest to declare.

Financial Disclosure: The author has declared that he did not receive any financial support for this study.

\section{References}

1. Djordjevic ML, Bumbasirevic MZ, Krstic Z, Bizic MR, Stojanovic $\mathrm{BZ}$, Miocinovic R, et al. Severe penile injuries in children and adolescents. Reconstruction modalities and outcomes. J. Urol 2014;83:465-70. [CrossRef]

2. Khaireddine B, Adnen H, Khaled BB, Adel S. Surgical reimplantation of penile glans amputation in children during circumcision. Urol Ann 2014;6:85-7. [CrossRef]

3. Hashem FK, Ahmed S, Al-malaq AA, Abudaia JM. Successful replantation of penile amputation (post-circumcision) complicated by prolonged ischaemia. Br J Plast Surg 1999;52:308-10. [CrossRef]

4. Jezior JR, Brady JD, Schlossberg SM. Management of penile amputation injuries. World J Surg 2001;12:1602-9. [CrossRef]
5. Ehrich WS. Two unusual penile injuries. J Urol 1929;21:239. [CrossRef]

6. Krishna Reddy SV, Shaik AB, Sreenivas K. penile injuries: A ten-year experience. Can Urol Assoc J 2014; 8(9-10): E626-31. [CrossRef]

7. Innocenti A, Tanini S, Mori F, Melita D, Innocenti M. Scrotal dartos-fascio-myo-cutaneous flaps for penis elongation after catastrophic iatrogenic skin shaft sub-amputation: A case of recovery using an extremely adaptable flap. Int J Surg Case Rep 2016;28:300-2. [CrossRef]

8. Morrison SD, Shakir A, Vyas KS, Kirby J, Crane CN, Lee JK. Phalloplasty: A review of techniques and outcomes. Plast Reconst Surg 2016;138:594-615. [CrossRef]

9. Angulo JC, Arance I, Esquinas C, Gomez M, FernandezCanamaque JL. Total phallic reconstruction using radial forearm free flap after iatrogenic penile amputation. Actas Urol Esp 2016;13:1119-24.

10. Bahnasawy MS, El-Sherbiny MT. Pediatric penile trauma. BJU Int 2002;90:92-6. [CrossRef]

11. Limaye RD, Hancock RA. Penile urethral fistula as a complication of circumcision. J Pediatr 1968;72:105-6. [CrossRef]

12. Mkony CA, Aboud M. Post-circumcision Urethro-cutaneous fistula: The key to successful reconstruction. East Cent Afr J Surg 2006;11:118-20.

13. Krill AJ, Palmer LS, Palmer JS. Complications of circumcision. ScientificWorldJounal 2011;11:2458-68. [CrossRef]

14. Ikuerowo SO,Bioku MJ,Omisanjo OA, Esho JO. Urethrocutaneous fistula complicating circumcision in children. Niger J Clin Pract 2014; 17:145-8. [CrossRef]

15. Baskin LS, Canning DA, Snyder HM, Duckett JW. Surgical repair of urethral circumcision injuries. J Urol 1997;158:2269-71. [CrossRef] 